\title{
HUBUNGAN ANTARA PERTUMBUHAN ROHANI ALUMNUS KRISTEN BERBASIS PEMURIDAN KELOMPOK TUMBUH BERSAMA KONTEKSTUAL DENGAN KINERJA PERINTISAN KELOMPOK TUMBUH BERSAMA KONTEKSTUAL
}

\author{
Irawan Budi Lukmono \\ Dosen Tetap Sekolah Tinggi Teologi Gamaliel Surakarta \\ Email: ibel_choy@yahoo.co.id \\ Lavandya Permata KW, SH \\ Dosen Tetap Sekolah Tinggi Teologi Gamaliel Surakarta \\ Email: lavandyavanny@gmail.com \\ F. Tri Handoko \\ Mahasiswa S-1 Sekolah Tinggi Teologi Gamaliel Surakarta \\ Email: hands.smith@yahoo.com
}

\begin{abstract}
Spiritual growth is the call of God for every Christian, including Christian scholars. Spiritual growth is impacting on all aspects of life Christian scholars, including the pioneering group discipleship ministry motivation to help others grow spiritually.

The purpose of this study was to find a relationship between spiritual growth of Christian scholar based on Contextual Bible Group (CBG-KTBK) with their pioneering performance Contextual Bible Group. The population in this study is an alumnus of Christians living in the area of Surakarta, Boyolali, Sukoharjo, Wonogiri, Sragen and Klaten as 80 active peoples in discipleship. The research sample of 40 peoples. Questionnaire valid for a total of 39 questionnaires were analyzed.

From the analysis of the study was the correlation coefficient $(r s)=0.8555$. Sig: 0,001 <0,05. Conclusion of this research is there are strong relationship, and the direction that is increasingly significant spiritual growth through Contekxtual Bible Group is increasingly performing well in the pioneering Contextual Bible Group.
\end{abstract}

Keywords: Alumnus Growth, Discipleship KTBK, Planting KTBK

ABSTRAK

Pertumbuhan rohani adalah panggilan Tuhan bagi setiap orang Kristen termasuk sarjana Kristen. Pertumbuhan rohani ini berpengaruh terhadap seluruh aspek hidup alumnus Kristen, termasuk motivasi pelayanan perintisan kelompok pemuridan untuk menolong orang lain bertumbuh secara rohani.

Tujuan penelitian ini adalah untuk menemukan hubungan pertumbuhan rohani alumnus berbasis pemuridan Kelompok Tumbuh Bersama Kontekstual dengan kinerja perintisan Kelompok Tumbuh Bersama Kontekstua (KTBK). Populasi dalam penelitian ini adalah alumnus Kristen yang tinggal di daerah Surakarta, Boyolali, Sukoharjo, Wonogiri, Sragen dan Klaten sebanyak 80orang yang aktif dalam pemuridan. Sampel penelitian 40 alumnus. Angket yang valid untuk dianalisa sebanyak 39 angket.

Dari hasil analisa penelitian ternyata koefisien korelasi $(r s)=0,8555$. Nilai sig: 0,001<0,05. Kesimpulan penelitian yaitu ada hubungan suat, signifikan dan searah yaitu semakin bertumbuh rohani 
alumnus Kristen melalui Kelompok Tumbuh Bersama Kontekstual maka semakin berkinerja baik dalam merintis Kelompok Tumbuh Bersama Kontekstual.

Kata kunci: Pertumbuhan Alumnus, Pemuridan KTBK, Perintisan KTBK

\section{A. PENDAHULUAN}

\section{Latar Belakang}

Amanat Agung Tuhan Yesus kepada para murid-Nya sebelum naik ke surga adalah "jadikanlah semua bangsa murid-Ku" (Matius 28: 19). Ini adalah perintah utama yang didukung dengan dua sub perintah lainnya yaitu "pergilah dan baptislah".

Kata "bangsa" dalam Bahasa Yunani menggunakan istilah "ethnos" diartikan: kaum atau orang-orang yang tidak mengenal Allah". Setiap murid Yesus memiliki tanggung jawab untuk menjadikan semua kaum yang tidak mengenal Allah agar menjadi murid Yesus.

Sarjana Kristen (alumnus) adalah konteks yang harus dimuridkan. Mereka adalah pribadipribadi yang telah mengenal Kristus dan mempunyai kebutuhan untuk menjadi murid Kristus yang dewasa penuh serupa dengan Kristus.

Melalui pelayanan pemuridan kontekstual yang ada yaitu pelayanan Kelompok Tumbuh Bersama Kontekstual (KTBK) diharapkan dapat menolong setiap alumnus Kristen bertumbuh spiritualitasnya. Salah satu buah kehidupan spiritualitas alumnus adalah motivasi dan perilakunya dalam memuridkan sesama alumnus.

Oleh karena itu, penulis tertarik mengadakan penelitian dengan topik hubungan pertumbuhan rohani alumnus berbasis pemuridan Kelompok Tumbuh Bersama Kontekstual dengan kinerja perintisan Kelompok Tumbuh Bersama Kontekstual.

\section{Batasan Masalah}

Batasan masalah yang ditetapkan hanya pada permasalahan mengenai hubungan hubungan pertumbuhan rohani alumnus berbasis pemuridan Kelompok Tumbuh Bersama Kontekstual dengan kinerja perintisan Kelompok Tumbuh Bersama Kontekstual.

\section{Rumusan Masalah}

Rumusan masalah dalam penelitian ini adalah apakah ada hubungan pertumbuhan rohani alumnus berbasis pemuridan Kelompok Tumbuh Bersama Kontekstual dengan kinerja perintisan Kelompok Tumbuh Bersama Kontekstual.

\section{Tujuan Penelitian}

Tujuan penelitian ini adalah untuk menemukan hubungan pertumbuhan rohani alumnus Kristen berbasis pemuridan Kelompok Tumbuh Bersama Kontekstual dengan kinerja perintisan Kelompok Tumbuh Bersama Kontekstual.

\section{Manfaat Penelitian}

Manfaat penelitian ini adalah pertama, secara teoritis, mengetahui hubungan hubungan pertumbuhan rohani alumnus Kristen berbasis pemuridan KTBK kinerja perintisan KTBK. Kedua, secara praktis, sebagai masukkan untuk mengembangkan perintisan KTBK dalam konteks pelayanan alumnus.

\section{B. KAJIAN PUSTAKA}

\section{Pertumbuhan Alumnus Kristen Berbasis Pemuridan Kelompok Tumbuh Bersama Kontekstual}

Manusia adalah mahluk yang diciptakan Allah menurut rupa dan gambar Allah sendiri. ${ }^{1}$ Namun ketika manusia itu memilih untuk memberontak terhadap Allah, rupa dan gambar Allah itu menjadi rusak. Kemuliaan Allah yang ada pada manusia itu menjadi hilang. ${ }^{2}$ Namun Allah yang penuh kasih mengutus Anak-Nya yang tunggal ke dalam dunia untuk menebus manusia berdosa. ${ }^{3}$

\footnotetext{
${ }^{1}$ Kejadian 1: 26-27, Mazmur 8: 3-10

${ }^{2}$ Kejadian 3-4:8,Yesaya 53,Roma 3:23, 6: 23

${ }^{3}$ Yohanes 3: 16, 1 Yohanes 4: 9-12
} 
Dan setiap orang yang menerimanya sebagai Tuhan dan Juru Selamat pribadi mengalami penulihan identitas diri yang telah rusak karena pemberontakan itu. ${ }^{4}$ Pertobatan bukan akhir dari kehidupan rohani seseorang tetapi awal kehidupan rohani yang berorientasi ke depan berupa pembangunan karakter ilahi menuju keserupaan dengan gambar Anak-Nya. ${ }^{5}$

Alumnus Kristen adalah anak-anak Allah yang telah menyelesaikana pendidikannya di Perguruan Tinggi. Sebagai anak-anak Allah tentunya panggilana hidup alumnus adalah terus bertumbuh hidup rohaninya menjadi pribadi yang dewasa serupa Kristus.

Salah satu sarana pertumbuhan rohani yang ada adalah melalui pemuridan kontekstual dengan bentuk Kelompok Tumbuh Bersama Kontekstual (KTBK). Berikut ini akan dijelaskan seluk beluk Pemuridan Kontekstual melalaui KTB Kontekstual.

\section{Pengertian}

Pemuridan diartikan sebuah proses menuntun orang lain untuk menerima Kristus dan menjadikannya pengikut yang setia belajar dari Tuhan. Dari segi praktis, pemuridan adalah pelayanan seutuhnya terhadap orang percaya ialah mendidik melalui pembinaan iman, dengan tujuan untuk mendewasakan setiap anggotanya dalam Kristus. Pemuridan juga diartikan dengan hubungan antara guru dan murid, didasarkan pada pola Kristus dan kehidupan-Nya yang diajarkan kepada muridNya.

\section{Dasar Teologis}

Dasar-dasar Alkitabiah tentang pemuridan dalam Perjanjian Lama antara lain: pertama, pada waktu istilah murid telah lama dikenal orang. Buktinya ada orang-orang yang menyebut dirinya murid Musa.

Kedua, Allah berfirman bagi orang tua agar mereka mengajarkan Firman Allah secara berulangulang kepada anak-anaknya (ulangan 6: 4-5). Berarti anak-anak itu sebagai murid dari orang tuanya.

\footnotetext{
${ }^{4}$ Yohanes 1: 12, 2 Korintus 5: 17

${ }^{5}$ Roma 8: $28-30$
}

Ketiga, pengakuan Nabi Yesaya bahwa Allah membuatnya sebagai seorang murid (Yesaya 50: 4)

Keempat, konsep murid yang dekat dengan konsep murid Kristus yaitu mereka yang menjadi murid-murid Yohanes Pembaptis.

Dasar-dasar Alkitab tentang Pemuridan dalam Perjanjian Baru antara lain, pertama, Amanat Tuhan Yesus dalam Matius 28: 19-20. Tuhan Yesus menghendaki agar orang-orang yang mengikut Dia dan menjadikan orang lain muridnya.

Kedua, dikuatkan dengan pelayanan Tuhan Yesus sendiri yaitu memanggil dan mengutus 12 orang sebagai murid-Nya (Matius 10: 1-4).

Ketiga, terlihat dari konsep pelayanan Paulus yang memuridkan dan menganjurkan agar Tomotius memuridkan orang lain (2 Timotius 2: 2).

Jadi, secara keseluruhan Alkitab, baik Perjanjian Lama maupun Perjanjian Baru mendukung adanya "pemuridan". Lebih daripada itu, pemuridan perlu dilaksanakan oleh orang Kristen, karena telah diamanatkan oleh Tuhan Yesus kepada Para Rasul.

\section{Tujuan}

Tujuan Pemuridan adalah untuk menyempurnakan setiap anak Tuhan dalam watak dan sikap sampai menjadi serupa dengan Kristus.

\section{Metode: KTB Kontekstual}

Kelompok Tumbuh Bersama Kontekstual (KTBK) adalah sekelompok murid Kristus terdiri dari 3-6 orang yang berkomitmen untuk bertumbuh dewasa serupa Kristus melalui: mempelajari Firman Tuhan, menaati Firman Tuhan, memiliki relasi yang saling bergantung satu dengan lainnya, dan melipatganda-kan KTBK baru.

Kelompok Tumbuh Bersama ini disebut KTB Kontekstual karena: konteks anggota sangat diperhatikan baik kebutuhan rohani maupun kevariasian setiap pribadi, pemahaman Alkitab secara induktif dengan metode penafsiran kontekstual, konteks relasi kelompok antara pemimpin dengan anggota bersifat fungsional-inter dependensi (saling kebergantungan), pertumbuhan 
rohani hanya terjadi dalam konteks tubuh Kristus, perencanaan program berorientasi pada tujuan dan sesuai konteks kebutuhan rohani, berkat-berkat KTBK dapat dibagikan kepada orang lain dalam konteks yang berbeda.

Visi atau tujuan KTBK adalah: murid Kristus akan bertumbuh sampai kedewasaan penuh di dalam Kristus melalui pembelajaran Firman Tuhan di dalam persekutuan tubuh Kristus (Matius 28: 19-20, Efesus 4: 11-16)

Misi KTBK adalah mendorong peserta bertumbuh dewasa serupa Kristus, melengkapi peserta pemahaman Alkitab, mengontrol peserta taat Firman Tuhan, mendelegasi anggota menjadi pemimpin KTB Kontekstual yang berkualitas.

Dalam melaksanakan KTB Kontekstual, ada empat unsur yang penting, yaitu: pertama, belajar Firman Tuhan (learning). Pengajaran Firman Tuhan harus disertai kerelaan dan menaatai otoritas Firman Tuhan. Proses belajar Firman Tuhan dilakukan bersama dengan menggunakan metode induktif kontekstual, didukung dengan pembacaan bukubuku-buku rohani, sharing antar pribadi, diskusi tentang iman Kristen, aksi ketaatan dan lain-lainnya. Proses belajar ini dilakukan pada periode waktu tertentu sesuai dengan kesepakatan antar anggota.

Kedua, penyembahan dan doa (worship). Penyembahan merupakan respon seseorang untuk memuji dan membesarkan nama Tuhan. KTBK tidak dapat dipisahkan dengan unsur penyembahan, karena unsur ini membuat anggota KTBK lebih mengenal Allah. Penyembahan dapat dilakukan melalui doa, puji-pujian, kidung, pembacaan mazmur puji-pujian dan puisi yang berisi pujipujian. Berdoa bersama adalah cara yang khusus untuk mengutarakan beban pribadi, meminta pimpinan Tuhan dan memohon berkat-Nya. Doa menjadi wujud nyata dari kerendahan hati dan ketergantungan seseorang kepada Tuhan.

Ketiga, persekutuan (fellowship). Persekutuan kasih yang terjadi diantara anggota KTBK akan menyaksikan kepada orang lain bahwa mereka benar-benar murid Kristus (Yohanes 13: 34-35). Persekutuan dalam KTBK akan menolong semua anggota dapat saling mengasihi, melayani, membangun, memperhatikan, mensharingkan kebutuhannya masing-masing, mengakui dosadosanya, menanggung beban, membesarkan hati orang lain dan mendoakan (Efesus 4, 1 Korintus 12 dan Roma 12).

Keempat, pengutusan (mission). KTBK terkait erat dengan pengutusan. Pengutusan adalah kesaksian anggota KTBK untuk pergi memberitakan Injil Yesus Kristus kepada orang-orang yang membutuhkannya. Melalui pengutusan ini anggota KTBK dapat mempraktekkan kasih dan kuasa Allah untuk mengubah kehidupan rohani dari setiap pribadi dan masyarakat luas. Misi lain yang dilakukan setiap anggota KTBK adalah membentuk KTBK baru dengan memimpin saudara seiman lainnya yang rindu bertumbuh.

Keempat unsur ini tidak dapat dipisahkan satu sama lain, melainkan bekerja bersama-sama untuk tercapainya tujuan KTBK.

Keberhasilan KTBK selain ditentukan oleh faktor anggota, pemimpin, materi yang berkualitas dan alkitabiah, juga harus didukung oleh peranan Roh Kudus.

Roh Kudus adalah Roh Kebenaran dan guru agung bagi orang percaya. Roh Kudus akan mengingatkan dan mengajarkan Firman Kebenaran yang pernah diajarkan oleh Tuhan Yesus (Yohanes 14: 16, 25-26). Roh Kudus adalah Roh Pemimpin. Ia berkarya memimpin orang percaya kepada seluruh kebenaran (Yohanes 16: 12-18). Roh Kudus adalah saksi Kristus di dunia. Ia berkarya menyaksikan Yesus Kristus kepada dunia bersama-sama dengan orang percaya (Yohanes 15: 26-27)

Melihat pribadi Roh Kudus diatas, maka nyatalah bahwa Roh Kudus adalah pribadi yang hadir dan berperan dalam kehidupan para murid dan Firman-Nya.

Secara khusus dalam KTBK Roh Kudus menumbuhkan kerinduan dan memberikan pengertian kepada pemimpin dan anggota KTBK akan Firman Tuhan. Selain itu, Roh Kudus juga akan mengingatkan pemimpin dan anggota KTBK untuk mentaati Firman Tuhan yang telah dipelajari.

\section{Kinerja Perintisan Kelompok Tumbuh Bersama Kontekstual}




\section{Motivasi Pelayanan Perintisan KTBK}

Setiap kali seseorang melakukan sesuatu, ia pasti memiliki suatu dorongan tertentu untuk mau melakukan hal itu. Dorongan itu disebut motivasi. Jadi motivasi adalah "daya gerak yang mencakup dorongan, alasan, dan kemauan yang timbul dalam diri seseorang yang menyebabkan dia berbuat sesuatu."

Pada umumnya dikenal 3 (tiga) bentuk motivasi. ${ }^{6}$ Pertama, motivasi ketakutan yaitu motivasi karena adanya rasa takut karena adanya paksaan dan resiko yang ditimbulkan sehingga ia melakukannya.

Kedua, motivasi imbalan, yaitu adanya imbalan bias berupa bisa pujian, prestise, promosi atau penghargaan.

Ketiga, motivasi sikap yaitu motivasi yang berhubungan erat dengan tujuan-tujuan yang bersifat pribadi yang sering disebut Motivasi Diri (Self Motivation).

Pada umumnya ada tiga sumber motivasi ${ }^{7}$ yaitu: pertama, biogenesis (keberadaan orang itu sendiri). Sumber motivasi biogenesis memdorong seseorang secara aktif dan agresif secara dini. Orang ini membangun motivasi diri dengan baik dana memiliki memiliki prinsip hidup yang amat kuat, dan rasa percaya diri yang amat besar.

Kedua, sosiogenetis (lingkungan sekitar). Kahadiran seseorang dalam lingkungan dimana orang-orang sekitarnya suka melayani akan membuat orang ini akan terdorong untuk melayani juga.

Ketiga, teogenesis yaitu dari Tuhan (supranatural). Rasul Paulus merupakan suatu contoh yang sangat jelas dimana Ia melayani dalam memberitakan Injil (Kisah 26:19) karena telah lebih dahulu dikasihi dan dilayani Tuhan Yesus.

Alkitab memberikan beberapa motivasi pelayanan, pertama ketaatan, yaitu ketaatan untuk melakukan perintah Tuhan yang memerintahkan kita

${ }^{6}$ http://www.gkpi.or.id/publikasi/read/18/mo tiva-si_pelayanan/

${ }^{7}$ Idem agar melayani Tuhan dan sesama, yaitu membuat orang yang kita layani semakin mengasihi Tuhan dengan segenap hati, jiwa dan kekuatan (Mat. 22:3739).

Kedua, Kasih, yaitu kasih akan sesama seperti yang dimiliki oleh Tuhan Yesus sendiri ketika Ia melihat orang banyak "lelah dan terlantar seperti domba yang tidak bergembala" (Mat. 9:36), terlebiih kepada mereka yang masih terhilang dalam dosa. Setiap jiwa amat berharga di hadapan Allah.

Ketiga, keteladanan, yaitu kerinduan meneladani apa yang Tuhan Yesus lakukan saat. Ia berkata bahwa Ia datang untuk melayani (Mrk. 10:45). Bahkan Ia mengatakan bahwa kita dimampukan melakukan pekerjaan yang lebih besar dari yang dilakukan-Nya (Yoh. 14:12).

Keempat, regeneratif yaitu melihat ke masa depan gereja dan kekristenan ada di tangan orangorang yang kita layani sekarang. Dalam konteks ini semua orang percaya dan hamba-hamba Tuhan layak memperhatikan teladan pelayanan Yesus dalam pengkaderan-Nya. Motivasi ini diharapkan melahirkan generasi muda ilahi bagi masa depan gereja (Mal. 2:15), serta mewariskan iman yang hidup itu kepada generasi yang kemudian (2 ikan Tim. 1:5).

Kelima, eskhatologis. Motivasi ini melihat jauh ke masa yang akan datong. Motivasi ini bersifat preventif yaitu mencegah agar tidak terjadi gap generation atau terjadinya kerusakan generasi muda (2 Timotius 3:1-5)

Seorang alumnus yang juga murid Kristus haruslah termotivasi untuk merintis kelompok pemuridan dalam konteks alumnus karena kasih dan ketaatan kepada Allah dan demi kemajuan rohani sesame orang percaya.

\section{Langkah-langkah Merintis Kelompok Tumbuh Bersama Kontekstual}

Seorang alumnus yang telah dimuridkan adalah seorang pemimpin. Sebagai pemimpin Kristen, salah satu tugasnya adalah memuridkan atau menggembalakan domba-domba kepunyaan Allah. ${ }^{8}$ 
Salah satu langkah praktis memuridkan adalah dengan merintis KTBK baru.

Langkah-langkah praktis yang ditempuh untuk memulai KTB Kontekstual adalah pertama, berdoa. Mereka yang terbeban untuk membagikan berkat-berkat KTBK kepada saudara seiman lainnya hendaknya berdoa terlebih dahulu. Mohon Tuhan mempertemukan dengan lima teman yang bersedia untuk membentuk KTBK baru.

Kedua, sharingkan visi misi KTBK kepada rekan-rekan seiman agar mereka mengerti tentang KTBK dan manfaat KTBK bagi kebutuhan rohani setiap pribadi. Sosialisasikan KTBK dipersekutuan, gereja dan pertemuan-pertemuan supaya rekan-rekan seiman (alumnus) ikut.

Ketiga, memotivasi rekan-rekan seiman agar memiliki kerinduan dan komitmen membentuk KTBK baru dalam satu periode tertentu (misalnya tiga bulan dan bertemu seminggu sekali). Carilah rekan seiman yang memiliki kebutuhan rohani yang sama dan kehomogenan budaya akan memudahkan terbentuknya KTBK baru.

Keempat, jika ada minimal dua rekan yang bersedia ikut KTBK segeralah dimulai dengan pertemuan pertama. KTBK diikuti tiga sampai maksimum enam orang.

Kelima, pertemuan pertama dalam KTBK adalah berdoa, berkenalan, mensharingkan kebutuhan rohani masing-masing anggota, membuat perjanjian kesepakatan, berkomitmen, rencanakan jadwal pertemuan, tentukan materi yang sesuai kebutuhan rohaninya dan lanjutkan pertemuan selanjutnya. ${ }^{9}$

\section{METODOLOGI PENELITIAN}

\section{Ancangan dan Rancangan Penelitian.}

Paradigma penelitian ini adalah ancangan positivis. Penelitian positivis bersandar pada kuantifikasi dalam pengumpulan data dan analisis

\footnotetext{
${ }^{8}$ Jerry C. Wofford, Kepemimpinan Kristen yang mengubahkan. (Yogyakarta: Andi Ofset, 2001), 129
}

${ }^{9}$ Jurnal Aletheia Edisi 03/04 data untuk menguji hipotesis yang telah ditetapkan. Sesuai dengan ciri-ciri di atas penelitian ini menggunakan metode kuantitatif bukan eksperimental. ${ }^{10}$

Penelitian kuantitatif ini menggunakan jenis penelitian korelasional dan deskriptif. Penelitian korelasional menjelaskan kaitan antara variabelvariabel yang telah ditentukan. Korelasional menekankan pola hubungan sebab akibat di antara variabel variabel, dan mencakup prediksi prilaku yang akan datang dari variabel yang akan diukur sebelum prilaku itu. Variabel yang diketahui ini untuk menentukan statistik korelasi yang akan digunakan dan untuk analisis pengujian. Dengan menggunakan kedua metode tersebut, diharapkan dapat memperoleh data yang sangat membantu peneliti dalam mengambil kesimpulan tentang hubungan antar variabel yang dikaji dalam penelitian ini. ${ }^{11}$

Penelitian ini terdiri dari dua variabel, yaitu:

1. Varabel bebas (X): Pertumbuhan Alumnus

Berbasis Kelompok Tumbuh Bersama

Kontekstual

2. Variabel terikat (Y): Kinerja Perintisan Kelompok Tumbuh Bersama Kontekstual

Variabel pertumbuhan alumnus berbasis Kelompok Tumbuh Bersama Kontekstual (X) dalam penelitian ini didefinisikan sebagai pelaksanaan KTBK dalam konteks alumnus dalam rangka menolong pertumbuhan rohaninya. Kinerja Perintisan Kelompok Tumbuh Bersama Kontekstual (Y) didefinisikan sebagai praktek perintisan KTBK dalam konteks alumnus.

Dengan demikian, kerangka berpikir dalam penelitian ini dapat dilihat dalam gambar berikut ini:

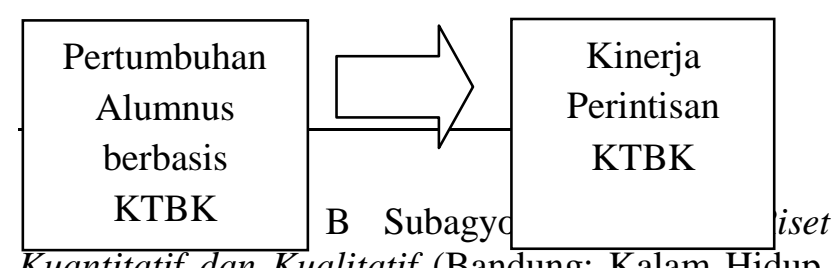
Kuantitatif dan Kualitatif (Bandung: Kalam Hidup, 2004)

\footnotetext{
${ }^{11}$ Ibid.,
} 
Gambar 1

\section{Variabel X mempengaruhi Variable $Y$}

Hipotesis dalam penelitian ini adalah "Semakin bertumbuh kerohanian alumnus melalui KTBK maka akan semakin baik kinerja dalam merintis KTBK baru"

Untuk pengujian maka hipotesis ini dideskripsikan lebih lanjut sebagai berikut:

Ho: Tidak ada korelasi antara pertumbuhan rohani alumnus melalui KTBK dengan kinerja perintisan KTBK.

H1: Semakin bertumbuh rohani alumnus melalui KTBK maka kinerja perintisan KTBK semakin baik.

Untuk mengetahui adanya hubungan pertumbuhan alumnus berbasis KTBK terhadap Kinerja perintisan KTBK, penulis menggunakan uji korelasi rank Pearson.

Sedangkan untuk pengambilan keputusan digunakan patokan sebagai berikut:

Jika probabilitas signifikansi $(\mathrm{Sig})<0,05$ maka Ho ditolak.

Jika probabilitas signifikansi $(\mathrm{Sig})>0,05$ maka Ho diterima.

Penelitian ini dilaksanakan pada bulan Desember 2014, dengan mengambil data dari para alumnus PMK yang tergabung dalam PAG (Persekutuan Alumnus Gamaliel).

\section{Populasi dan Sampel}

Populasi dalam penelitian ini adalah alumnus mahasiswa Kristen yang tinggal di daerah Surakarta, Boyolali, Sukoharjo, Wonogiri, Sragen dan Klaten sebanyak 80 alumnus yang aktif dalam pemuridan. Oleh karena populasi penelitian relatif sedikit maka sampel penelitian diambil sebesarbesarnya 40 alumnus.

\section{Alat Pengumpulan Data}

Alat pengumpulan data menggunakan angket dengan skala Likert. Pengukuran jawaban pertanyaan dalam angket disediakan dalam 4 (empat) tingkat jawaban.

Tabel Skor dalam skala likert

\begin{tabular}{|l|c|c|}
\hline Jawaban & Score/ \\
\multicolumn{2}{l|}{} & Nilai \\
\hline Sangat Setuju & SS & 4 \\
Setuju & S & 3 \\
Tidak Setuju & TS & 2 \\
Sangat Tidak Setuju & STS & 1 \\
\hline
\end{tabular}

\section{Uji Validitas Instrumen}

Untuk mengetahui apakah alat ukur atau alat pengumpul data dapat menghasilkan data yang valid dan reliable perlu adanya uji validitas dan uji reliabilitas. Uji Validitas bertujuan untuk mengetahui apakah instrument tersebut dapat digunakan untuk mengukur apa saja yang hendak diukur. ${ }^{12}$

Dalam memeriksa dan memastikan validitas instrument, peneliti menggunakan jenis validitas isi (Content Validity) dan Validitas Konstruk (Construct Validity), yakni kecocokan alat pengumpul data dengan sifat atau ciri hipotesis yang dirancang pada alt itu. ${ }^{13}$ Sedangkan untuk distribusi data dilakukan uji Normalitas.

\section{Prosedur Pengumpulan dan Analisis Data}

Prosedur Pengumpulan Data yaitu, pertama mencari daftar alumnus yang bertumbuh rohaninya melalui KTB Kontekstual. Dari 40 angket yang disebar dan diterima kembali terdapat 39 angket yang valid untuk dianalisa.

Untuk mengetahui ada tidaknya hubungan pertumbuhan alumnus berbasis pemuridan

\section{${ }^{12}$ Sugiyono, Statistika Untuk Penelitian} (Bandung: Alfabeta, 2007), 348

\footnotetext{
${ }^{13}$ Subagyo, 233
} 
kontekstual KTBK terhadap Kinerja Perintisan KTBK, digunakamn uji korelasi rank Pearson menggunakan SPSS.

\section{HASIL PENELITIAN DAN PEMBAHASAN}

Hasil analisis korelasi Pearson's rho (rs) hubungan antara pertumbuhan alumnus berbasis pemuridan kontekstual KTBK terhadap Kinerja Perintisan KTBK, sebagai berikut:

\begin{tabular}{|cl|r|r|}
\hline & & & \\
\hline VAR00001 & $\begin{array}{l}\text { Pearson } \\
\text { Correlation } \\
\text { Sig. (2- } \\
\text { tailed) } \\
\mathrm{N}\end{array}$ & 1 & .855 \\
VAR00002 & $\begin{array}{l}\text { Pearson } \\
\text { Correlation } \\
\text { Sig. (2- } \\
\text { tailed) } \\
\mathrm{N}\end{array}$ & .855 & .000 \\
\hline
\end{tabular}

Berdasarkan hasil analisa data di atas ternyata koefisien korelasi (rs) $=0,8555$ (berarti kedua variable Kuat. Nilai sig: $0,001<0,05$, artinya terhadap hubungan yang signifikan antar dua variable. Tanda positif menunjukkan bahwa korelasi yang terjadi antara skala 1 dan skala 2 adalah hubungan yang berbanding lurus, artinya semakin besar skala 1 maka semakin tinggi pula skala 2, karena koefisien korelasi positif, maka hubungan kedua variabel searah. Searah artinya jika variabel $x$ nilainya tinggi maka variabel $y$ juga tinggi. Kesimpulannya: hubungan skala 1 dan 2 kuat, signifikan dan searah.

\section{KESIMPULAN}

Dari penelitian ini disimpulkan bahwa ada hubungan yang kuat dan positif antara pertumbuhan rohani alumnus Kristen berbasis pemuridan KTBK dengan kinerja perintisan KTBK. Semakin baik pertumbuhan alumnus melalui KTBK berdampak semakin baik pula kinerja perintisan KTBk Baru.

\section{DAFTAR KEPUSTAKAAN}

Alkitab, Jakarta: LAI, 1995

http://www.gkpi.or.id/publikasi/read/18/motivasi_pelayanan/

"Pemuridan Kelompok Tumbuh Bersama Kontekstual" Jurnal Aletheia Edisi 03/04, STTG-PMKS, t.th.

Subagyo, Andreas B, Pengantar Riset Kuantitatif dan Kualitatif. Bandung: Kalam Hidup, 2004

Sugiyono, Statistika Untuk Penelitian. Bandung: Alfabeta, 2007.

Wofford, Jerry, C, Kepemimpinan Yang Mengubahkan. Yogyakarta: Andi Offset, 2001 